\title{
Development of a Detailed Kinetic Model for Hydrogen Oxidation in Supercritical H2O/CO2 Mixtures
}

\section{Li, Guoxing; Lu, Youjun; Glarborg, Peter}

Published in:

Energy and Fuels

Link to article, DOI:

10.1021/acs.energyfuels.0c01914

Publication date:

2020

Document Version

Peer reviewed version

Link back to DTU Orbit

Citation (APA):

Li, G., Lu, Y., \& Glarborg, P. (2020). Development of a Detailed Kinetic Model for Hydrogen Oxidation in Supercritical $\mathrm{H}_{2} \mathrm{O} / \mathrm{CO}$ Mixtures. Energy and Fuels, 34(12), 15379-15388.

https://doi.org/F0.102 Hacs.energyfuels.0c01914

\section{General rights}

Copyright and moral rights for the publications made accessible in the public portal are retained by the authors and/or other copyright owners and it is a condition of accessing publications that users recognise and abide by the legal requirements associated with these rights.

- Users may download and print one copy of any publication from the public portal for the purpose of private study or research.

- You may not further distribute the material or use it for any profit-making activity or commercial gain

- You may freely distribute the URL identifying the publication in the public portal

If you believe that this document breaches copyright please contact us providing details, and we will remove access to the work immediately and investigate your claim 
Development of a detailed kinetic model for hydrogen oxidation in supercritical $\mathrm{H}_{2} \mathrm{O} / \mathrm{CO}_{2}$ mixtures

\section{Guoxing $\mathrm{Li}^{1}$, Youjun $\mathrm{Lu}^{1 *}$, Peter Glarborg ${ }^{2 *}$}

1. State Key Laboratory of Multiphase Flow in Power Engineering, Xi'an Jiaotong University, Xi'an, Shaanxi, 710049, PR China

2. Department of Chemical and Biochemical Engineering, Technical University of Denmark, 2800 Lyngby, Denmark

Submitted to

\section{Energy \& Fuels}

* Corresponding author. Tel.:+86-29-82664345; Fax: +86-29-8266-9033

E-mail: yjlu@mail.xjtu.edu.cn (Youjun Lu)

* Corresponding author. Tel.:+45-845252840; Fax: +45-45882258

E-mail: pgl@kt.dtu.dk (Peter Glarborg) 
Abstract: The application of hydrogen as a fuel or auxiliary fuel has extended beyond gas-phase conditions. This paper reports the development of a detailed chemical kinetic model for hydrogen oxidation in supercritical $\mathrm{H}_{2} \mathrm{O} / \mathrm{CO}_{2}$ mixtures, based on an existing gas-phase model. Revisions were made to thermodynamic properties and elementary reactions to account for the supercritical conditions. The effect of supercritical water (SCW) on selected elementary reactions was taken into consideration. The model for SCW oxidation of hydrogen was evaluated against experimental data in literature. The model was able to reproduce satisfactorily the experimental results. The observed discrepancies were largely attributed to experimental artifacts, mainly deviation from ideal plug flow. Key elementary reactions were identified by sensitivity analysis and details of the oxidation mechanism was inferred by analyzing reaction paths. Finally, effects of pressure and $\mathrm{CO}_{2}$ concentration on the model predictions were discussed.

Keywords: Hydrogen oxidation; Model development; Kinetic modeling; Supercritical mixtures. 


\section{Introduction}

The prospect of a hydrogen-based economy ${ }^{1}$ has promoted interest in extending the use of hydrogen as a fuel to many industrial fields. A novel example is the use of hydrogen as a supplemental fuel in a power generation system, which is based on supercritical water gasification (SCWG) of coal/biomass combined with a supercritical multi-staged steam turbine. ${ }^{2,3}$ This technology provides a new way for clean utilization of coal/biomass and effectively avoids $\mathrm{SO}_{\mathrm{x}}, \mathrm{NO}_{\mathrm{x}}$, and dust emissions. After being pumped into the gasifier, the organic material in the solid fuel is completely converted to $\mathrm{H}_{2}$ and $\mathrm{CO}_{2}$ through gasification reactions. Then the supercritical $\mathrm{H}_{2} \mathrm{O} / \mathrm{CO}_{2} / \mathrm{H}_{2}$ mixture flows into a combustor, where hydrogen is further oxidized to water. The released thermal energy reheats the supercritical working medium. Afterwards the single-phase supercritical mixture enters the steam turbine for power generation.

Hydrogen is also a major intermediate during supercritical water oxidation $(\mathrm{SCWO})^{4,5}$ processes, a promising technology for complete destruction of hazardous organic wastes. Knowledge of the kinetics of hydrogen oxidation in supercritical $\mathrm{H}_{2} \mathrm{O} / \mathrm{CO}_{2}$ mixtures is important to improve operation and design of these combustors. Studies on hydrogen oxidation in supercritical fluids started in the 1990s. The pioneering work was conducted by Holgate et al., ${ }^{6}$ who studied the kinetics of hydrogen oxidation in supercritical water (SCW) in a flow reactor. They established an empirical rate expression and compared also the experimental data to the detailed gas-phase $\mathrm{H}_{2} / \mathrm{O}_{2}$ mechanism of Yetter et al., ${ }^{7}$ correcting for the high-pressure environment. Holgate et al. later modified the model to reproduce better the observed effect of pressure on the reaction rate. ${ }^{8}$ Alkam et al. ${ }^{9}$ refined the rate constants of some highlysensitive elementary reactions in the model of Holgate et al. ${ }^{6}$ and took it as a subset of the reaction mechanism for methanol oxidation in SCW. Brock et al. ${ }^{10}$ developed a kinetic model for SCWO of $\mathrm{C}_{1}$ compounds and hydrogen. Their model did a good job at high temperatures but was less accurate as the temperature decreased toward the critical point, possibly due to the use of the ideal gas law. Recently, Kallikragas et al. ${ }^{11}$ and $\mathrm{Li}$ et al. ${ }^{12}$ conducted experiments in flow reactors on hydrogen oxidation in SCW. 
They derived overall kinetic parameters, but did not analyze details of the reaction kinetics. In further work, $\mathrm{Li}$ et al. ${ }^{13}$ investigated the hydrogen oxidation process in supercritical mixtures on the atomic level using molecular dynamics (MD) simulations.

The objective of the present study is to develop a detailed chemical kinetic model to simulate hydrogen oxidation in supercritical $\mathrm{H}_{2} \mathrm{O} / \mathrm{CO}_{2}$ mixtures. The kinetic model for high-pressure gas-phase oxidation of $\mathrm{H}_{2}$ by Hashemi et al. ${ }^{14}$ is revised to account for the SCW environment. The Peng-Robinson (PR) equation is used to calculate values of SCW densities. Predictions with the model are compared to the experimental data from Holgate et al., ${ }^{6,8}$ Kallikragas et al., ${ }^{11}$ and Li et al. ${ }^{12}$ on SCWO of $\mathrm{H}_{2}$. Discrepancies between data and modeling results are discussed in terms of experimental and modeling uncertainties. Important elementary reactions are identified by sensitivity and reaction path analyses. The effects of pressure and $\mathrm{CO}_{2}$ concentration on the reaction kinetics are discussed. The work yields insight into the intrinsic reaction mechanism of hydrogen oxidation under supercritical conditions and may facilitate reactor design in relevant industrial applications.

\section{Chemical kinetic model}

Numerous chemical kinetic models for hydrogen oxidation in gas phase have been reported in the past decades. Mueller et al. ${ }^{15}$ conducted experiments to measure profiles of the $\mathrm{H}_{2} / \mathrm{O}_{2}$ reaction in a variable pressure flow reactor and proposed a kinetic model whose predictions were in good agreement with the experimental data. Li et al. ${ }^{16}$ and later Burke et al. ${ }^{17}$ made revisions to this model to improve the model performance. The model of Burke et al. ${ }^{17}$ was updated by Hashemi et al. ${ }^{14}$ and validated against a wide range of high-pressure data, including results obtained at 50 bar and temperatures of $427-627{ }^{\circ} \mathrm{C}$ in a high pressure laminar flow reactor. O Conaire et al. ${ }^{18}$ based their mechanism on the work of Mueller et al. ${ }^{15}$ and tested it rigorously against a wide range of experimental data for combustion of $\mathrm{H}_{2} / \mathrm{O}_{2}$ mixtures. Their model was subsequently updated to describe both hydrogen and syngas mixture oxidation at elevated pressure. ${ }^{19}$ Other hydrogen/syngas oxidation models have been published by Konnov, ${ }^{20-22}$ Varga et 
al., ${ }^{23,24}$ Davis et al., ${ }^{25}$ Sun et al. ${ }^{26}$ and Hong et al. ${ }^{27}$ Olm et al. ${ }^{28}$ tested the performance of 19 published hydrogen combustion mechanisms against available experimental data and ranked the best mechanisms for different kinds of experiments. Common for these models are that they are intended for gas-phase conditions.

Solvent effects under supercritical conditions were discussed by Sandler et al. ${ }^{29}$ Reactions in SCW most likely proceed as free-radical reactions rather than ionic reactions since the ionic dissociation product of water $\left(K_{w}\right)$ is about $10^{-23}$ at $450-600{ }^{\circ} \mathrm{C}$, implying that SCW only weakly dissociates and poorly solvates ions. ${ }^{30,31}$

In Supporting Information (SI), predictions of five detailed mechanisms from the literature ${ }^{14,16,17,19,20}$ are compared with the experimental data obtained in our previous study $^{12}$ (Figure S1). None of the models provides a satisfactory prediction of the SCWO results. The kinetic model proposed by Hashemi et al. ${ }^{14}$ that has been comprehensively tested at high pressures and intermediate temperatures is selected as the basis of the present study. The key reactions important under supercritical conditions were reevaluated in the present work, as discussed in the following sections. The $\mathrm{C}_{1}$ submechanism added to the present model was taken without modification from the highpressure methane oxidation mechanism of Hashemi et al. ${ }^{32}$ The full model is available in Table S1 (SI). The reference numbers of the elementary reactions mentioned below refer to this table. An abbreviated version of the mechanism, including the eight most important reactions under SCWO conditions, is listed in Table 1.

Table 1. Abbreviated $\mathrm{H}_{2} / \mathrm{O}_{2}$ reaction mechanism. $k=A T^{n} \exp \left(-E_{a} / R T\right)$ in units of $\mathrm{cm}^{3} / \mathrm{mol} / \mathrm{s} / \mathrm{cal}$.

\begin{tabular}{cllrrc}
\hline No. & Reaction & $\mathrm{A}$ & $\mathrm{n}$ & $\mathrm{E}_{\mathrm{a}}$ & Ref. \\
\hline 5 & $\mathrm{H}+\mathrm{O}_{2}=\mathrm{O}+\mathrm{OH}$ & $1.0 \mathrm{E} 14$ & 0.00 & 15290 & {$[46]$} \\
7 & $\mathrm{OH}+\mathrm{H}_{2}=\mathrm{H}+\mathrm{H}_{2} \mathrm{O}$ & $4.4 \mathrm{E} 13$ & 0.00 & 6990 & {$[47]$} \\
9 & $\mathrm{H}+\mathrm{O}_{2}(+\mathrm{M})=\mathrm{HO}_{2}(+\mathrm{M})$ & $4.7 \mathrm{E} 12$ & 0.44 & 0 & {$[36,37]$} \\
& Low pressure limit & $1.2 \mathrm{E} 19$ & -1.20 & 0 & {$[38]$} \\
& $\mathrm{F}_{\text {cent }}=0.5$ & & & & \\
& $\varepsilon_{\mathrm{H} 2 \mathrm{O}}=16.6, \varepsilon_{\mathrm{CO} 2}=3.61, \varepsilon_{\mathrm{H} 2}=1.5$ & & & & \\
13 & $\mathrm{HO}_{2}+\mathrm{OH}=\mathrm{H}_{2} \mathrm{O}+\mathrm{O}_{2}{ }^{a}$ & $1.9 \mathrm{E} 20$ & -2.49 & 584 & {$[48]$} \\
& & $1.2 \mathrm{E} 09$ & 1.24 & -1310 & \\
\hline
\end{tabular}




\begin{tabular}{lllrrr}
\hline 14 & $\mathrm{HO}_{2}+\mathrm{HO}_{2}=\mathrm{H}_{2} \mathrm{O}_{2}+\mathrm{O}_{2}{ }^{a}$ & $1.0 \mathrm{E} 14$ & 0.00 & 11040 & {$[49,50]$} \\
& & $1.9 \mathrm{E} 11$ & 0.00 & -1409 & \\
15 & $\mathrm{H}_{2} \mathrm{O}_{2}(+\mathrm{M})=\mathrm{OH}+\mathrm{OH}(+\mathrm{M})$ & $2.0 \mathrm{E} 12$ & 0.90 & 48750 & {$[42]$} \\
& Low pressure limit & $2.5 \mathrm{E} 24$ & -2.30 & 48750 & {$[42]$} \\
& $\mathrm{F}_{\text {cent }}=0.42$ & & & & \\
& $\varepsilon_{\mathrm{H} 2 \mathrm{O}}=7.5, \varepsilon_{\mathrm{H} 2 \mathrm{O} 2}=7.7, \varepsilon_{\mathrm{CO} 2}=1.6, \varepsilon_{\mathrm{H} 2}=3.7$, & & & \\
& $\varepsilon_{\mathrm{O} 2}=1.2, \varepsilon \mathrm{CO}=2.8$ & & & & \\
16 & $\mathrm{H}_{2} \mathrm{O}_{2}+\mathrm{H}=\mathrm{HO}_{2}+\mathrm{H}_{2}$ & $1.7 \mathrm{E} 12$ & 0.00 & 3755 & {$[45]$} \\
19 & $\mathrm{H}_{2} \mathrm{O}_{2}+\mathrm{OH}=\mathrm{HO}_{2}+\mathrm{H}_{2} \mathrm{O}^{a}$ & $1.7 \mathrm{E} 12$ & 0.00 & 318 & {$[51]$} \\
& & $7.6 \mathrm{E} 13$ & 0.00 & 7269 & \\
\hline
\end{tabular}

$a$ : duplicate reaction; the resulting rate constant is the sum of the two Arrhenius expressions.

\subsection{Thermodynamic properties}

The ideal gas law cannot describe accurately the P-V-T relationship of reacting mixtures under SCWO conditions, and cubic equations of state are chosen to address real-gas effects associated with high-pressure reaction. Using Chemkin Pro 18.2, ${ }^{33}$ we compared the true densities of SCW with the values calculated by different models over a range of temperature, as shown in Figure S2 (SI). It was found that the Peng-Robinson (PR) equation ${ }^{34}$ produced a more accurate estimate of SCW densities than the SoaveRedlich-Kwong (SRK) equation. The PR equation of state, therefore, was adopted to calculate the densities of SCW and other species. The detailed parameters used in the equation for different species are listed in Table S2 (SI).

The thermodynamic properties including specific heat capacity $\left(\mathrm{C}_{\mathrm{p}}\right)$, enthalpy $(\mathrm{H})$ and entropy (S) are important in determining the chemical reaction equilibria. In Chemkin, it is presumed that these species properties at standard state are functions of temperature only. However, this calculation method cannot produce correct thermodynamic values at supercritical conditions since it neglects the effect of high pressure. The problem, if not properly handled, will cause erroneous simulation results. Consequently, we obtained thermodynamic values of different species at supercritical pressure from the NIST database. The data were then fitted using a piecewise polynomial with seven coefficients upon two temperature ranges. The fitting coefficients of different species upon different temperature ranges are listed in Table S3 (SI). With the fitting expressions, the calculated specific heat capacity and enthalpy 
were in good agreement with the true thermodynamic values under our simulation conditions, as shown in Figure S3 (SI).

\subsection{Reaction mechanism}

High pressure is one of the distinguished characteristics of the supercritical state. Below, we discuss the rate constants of the key pressure-dependent reactions, especially the high-pressure limits, as well as reactions, which show high sensitivity under supercritical conditions (referring to Figure 6 below).

\subsection{1. $\mathrm{H}+\mathrm{O}_{2}(+\mathrm{M})=\mathrm{HO}_{2}(+\mathrm{M})(\mathrm{R} 9)$.}

This chain propagation reaction, which competes with $\mathrm{H}+\mathrm{O}_{2}=\mathrm{O}+\mathrm{OH}(\mathrm{R} 5)$, is the main pathway for the production of $\mathrm{HO}_{2}$ radical and plays an important role in highpressure combustion. Janik et al. ${ }^{35}$ investigated experimentally the reaction of $\mathrm{H}$ atom with $\mathrm{O}_{2}$ in pressurized water up to $350{ }^{\circ} \mathrm{C}$ at $25 \mathrm{MPa}$. It was found that diffusion limitations were negligible at temperatures above $200{ }^{\circ} \mathrm{C}$ and the high-temperature rate constant was in near-perfect agreement with the gas-phase high-pressure limiting rate. Fernandes et al. ${ }^{36}$ studied R9 experimentally in a high-pressure flow cell over the temperature range $27-627^{\circ} \mathrm{C}$ and the pressure range $1.5-950$ bar. They determined a high-pressure limit in good agreement with the results obtained by Troe. ${ }^{37}$ The rate constant was also in agreement with the results by Janik et al. ${ }^{35}$ in the case of water as collision partner, proving the value to be reliable also for SCWO conditions. We combine the high pressure limit of Fernandes et al. ${ }^{36}$ and Troe ${ }^{37}$ with the low pressure limit recently reported by Shao et al. ${ }^{38}$ to obtain a set of rate coefficients for R9 valid over a wide range of pressure.

\subsection{2. $\mathrm{H}_{2} \mathrm{O}_{2}(+\mathrm{M})=2 \mathrm{OH}(+\mathrm{M})(\mathrm{R} 15)$.}

The dissociation of hydrogen peroxide is a main source of $\mathrm{OH}$ radicals in SCWO and shows a high sensitivity for the predicted consumption rate of hydrogen. Janik et al. ${ }^{39}$ measured the rate constant for the self-recombination of the $\mathrm{OH}$ radical in pressurized water from 150 to $350{ }^{\circ} \mathrm{C}$ using transient optical absorption spectroscopy. Their results showed that the water solvent had very little impact on the reaction path and the gas- 
phase high-pressure limit predicted well the temperature behavior of the rate constant. Sellevag et al. ${ }^{40}$ investigated the potential energy hypersurface of the reaction using high-level quantum chemistry methods and calculated the high-pressure limit. Hong et al. ${ }^{41}$ performed a shock tube study at 1.8 bar and suggested a new low-pressure limit. Troe $^{42}$ derived a pressure-dependent rate constant expression based on a review of experimental and theoretical studies of R15. The Troe rate constant expression, which covers a wide range of temperature and pressure and has good agreement with previously reported studies, was implemented in the present model.

\subsection{3. $\mathrm{H}+\mathrm{H}_{2} \mathrm{O}_{2}=\mathrm{HO}_{2}+\mathrm{H}_{2}(\mathrm{R} 16)$.}

This reaction, proceeding in the reverse direction, exhibits the highest sensitivity for $\mathrm{H}_{2}$ oxidation under SCWO conditions. An Arrhenius plot comparing reported rate constants for R16 is shown in Figure S4 (SI). Ellingson et al. ${ }^{43}$ computed the rate constant using ab initio methods. Their calculation is similar to the recommendation of Tsang et al. ${ }^{44}$ at temperatures below $700{ }^{\circ} \mathrm{C}$. However, their rate constant is $2-3$ times higher than the one recommended by Baulch et al. ${ }^{45}$ and will lead to much faster consumption of hydrogen than observed experimentally when incorporated into the kinetic model. So the reaction rate constant recommended by Baulch et al. ${ }^{45}$ is adopted in the present model.

The reactions $\mathrm{H}+\mathrm{O}_{2}=\mathrm{O}+\mathrm{OH}(\mathrm{R} 5), \mathrm{OH}+\mathrm{H}_{2}=\mathrm{H}+\mathrm{H}_{2} \mathrm{O}(\mathrm{R} 7), \mathrm{OH}+\mathrm{HO}_{2}=\mathrm{O}_{2}+$ $\mathrm{H}_{2} \mathrm{O}(\mathrm{R} 13), 2 \mathrm{HO}_{2}=\mathrm{H}_{2} \mathrm{O}_{2}+\mathrm{O}_{2}(\mathrm{R} 14)$ and $\mathrm{OH}+\mathrm{H}_{2} \mathrm{O}_{2}=\mathrm{HO}_{2}+\mathrm{H}_{2} \mathrm{O}$ (R19) are also important for the model performance. Discussions of these reactions are included in the Supporting Information.

\section{Results and discussion}

Predictions with the kinetic model was compared to the experimental data on SCWO of $\mathrm{H}_{2}$ from Holgate et al., ${ }^{6,8}$ Kallikragas et al., ${ }^{11}$ and Li et al. ${ }^{12}$ Details of the experimental conditions are listed in Table 2. It was assumed in the modeling that the reactors could be regarded as ideal plug-flow reactors. The actual conditions, however, deviated from idealization and this should be considered when comparing experiments 
and modeling results. For this reason, we have carefully reviewed the details of reactor design and experimental procedures to assess the possible uncertainties of each experimental work.

Table 2. Summary of experimental conditions for hydrogen oxidation under supercritical conditions in literatures.

\begin{tabular}{lccc}
\hline & Holgate et al..$^{6,8}$ & Kallikragas et al. $^{11}$ & Li et al. $^{12}$ \\
\hline Temperature range $/{ }^{\circ} \mathrm{C}$ & $495-600$ & $500-650$ & $503-600$ \\
Pressure $\mathrm{MPa}$ & 24.6 & 25 & 23.6 \\
Reaction medium & $\mathrm{SCW}$ & $\mathrm{SCW}$ & $\mathrm{SCW} / \mathrm{CO}_{2}$ \\
Equivalence ratio $\varphi^{\mathrm{a}}$ & $0.063-5.91$ & 0.89 & $0.46-1.23$ \\
Inlet $\mathrm{H}_{2}$ & & & \\
concentration $/ \mathrm{mol} \cdot \mathrm{L}^{-1}$ & $(0.385-3.69) \times 10^{-3}$ & $(3.12-4.31) \times 10^{-5}$ & $(0.81-1.04) \times 10^{-1}$ \\
Residence time/s & $3.4-11.0$ & $11.1-25.6$ & $3.0-19.7$ \\
Reactor material & Inconel 625 & Alloy $800 \mathrm{H}$ & $316 \mathrm{~L}$ \\
Reactor diameter $/ \mathrm{mm}$ & 1.71 & 2.159 & 3.86 \\
Reynolds number & $2700-5800$ & $200-400$ & $2300-4000$ \\
\hline
\end{tabular}

${ }^{\mathrm{a}}$ The fuel equivalence ratio $\varphi$ is expressed as $\left.\left(\left[\mathrm{H}_{2}\right]_{\text {in }} /\left[\mathrm{O}_{2}\right]_{\text {in }}\right)_{\text {actual }} /\left(\left[\mathrm{H}_{2}\right] \text { in } /\left[\mathrm{O}_{2}\right]_{\text {in }}\right)_{\text {stoich }}\right)$.

\subsection{Model evaluation}

3.1.1 Comparison with the data of Holgate et al.

In the experiments of Holgate et al., ${ }^{6,8}$ two agitated saturators filled with high-purity water were used to prepare the feed solutions. Oxygen and hydrogen were dissolved in water in saturators with pressure adjusted to achieve the desired concentrations. Two feeds were separately heated to the target temperature in a fluidized sand bath. Then they were mixed in a high-pressure cross fitting at the top of the reactor, where the oxidation reaction was initiated. Two sheathed thermocouples were used to measure the fluid temperatures at the point of mixing and at the exit of the reactor, respectively, and their average was taken as the reactor temperature.

Figure 1 compares the measured and predicted hydrogen conversion at $550{ }^{\circ} \mathrm{C}$. Presumably, the initiation of the reaction was affected by the presence of a mixing zone at the entrance of the reactor. The mixing process creates local pockets with fuel-lean and fuel-rich mixtures, respectively. Since the generation of the radical pool is affected by the local stoichiometry, the finite-rate mixing can be expected to influence the induction time. Analysis of $\mathrm{CO} / \mathrm{H}_{2}$ oxidation in a turbulent flow reactor by Yetter and 
coworkers $^{52,53}$ has shown that the kinetics at temperatures similar to those of SCWO are fast, under both fuel-lean and fuel-rich conditions. This permits the local chemistry to adjust rapidly as the fluid approaches radial uniformity. Their findings indicate that disturbances in the radical pool affect the induction chemistry only. Consequently, the consumption of major reactants can be modeled, but not the induction chemistry. Thus for comparison of the model predictions to experimental observations, the problem of not knowing the induction time is overcome by shifting the experimental data to match the calculated data at a reference point during the consumption of the major reactants. Following Yetter et al., ${ }^{52,53}$ comparison between the predictions and experimental results were performed by matching the point at which $50 \%$ of the experimentally observed hydrogen conversion occurred. The modeling predictions capture the overall trends of the experimental data, but the hydrogen conversion is overpredicted at long residence times. Unfortunately, no time-dependent data were reported for experiments conducted at other temperatures or stoichiometries. Due to the uncertainty in the initiation, these data were not used for model evaluation.

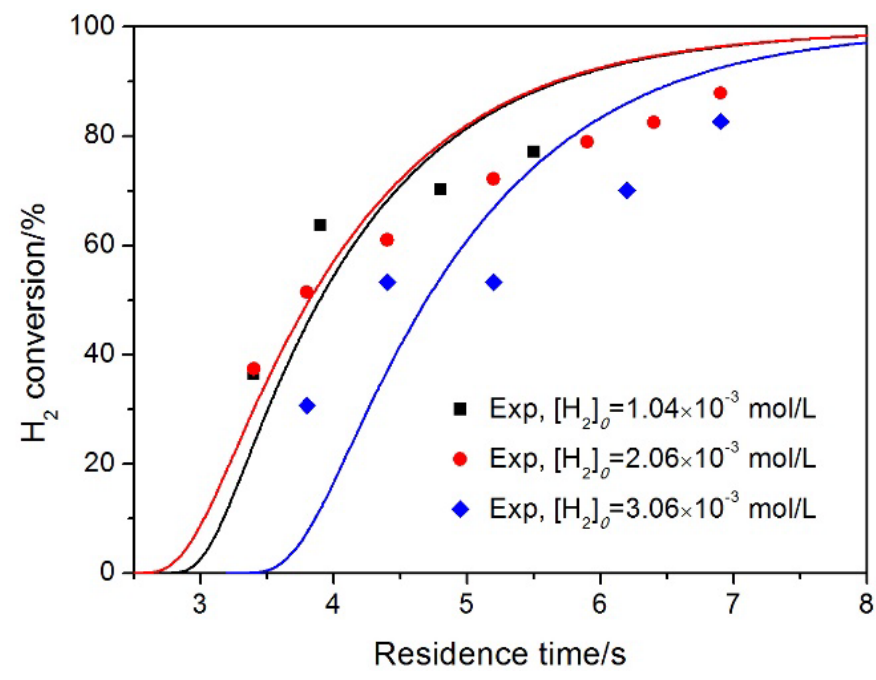

Figure 1. Comparison of measured ${ }^{6,8}$ and predicted hydrogen conversion as a function of residence time. Experimental condition: $\mathrm{T}=550{ }^{\circ} \mathrm{C}, \mathrm{P}=24.6 \mathrm{MPa}, \varphi=0.99$. The modeling curves have been shifted in time to match the point where $50 \%$ of the experimental hydrogen conversion occurs. 


\subsubsection{Comparison with the data of Kallikragas et al.}

The experiments of Kallikragas et al. ${ }^{11}$ were similar to those of Holgate et al., ${ }^{6,8}$ with the difference that the reactor was operated in the laminar flow regime. Furthermore, it was fed with oxygen-saturated water for a long time to oxidize the surface before experiments. Thereby an oxide film formed, eliminating consumption of oxygen by the surface. Figure 2 compares the hydrogen conversion predicted by the kinetic model with the experimental results reported by Kallikragas et al. The model provides a satisfactory agreement with the data at high temperatures, while it slightly overpredicts the hydrogen conversion at long residence times at $500{ }^{\circ} \mathrm{C}$. However, the data of Kallikrakas et al. are less useful for model evaluation than those of Holgate et al., because all the data were obtained at long residence times and at a high degree of conversion.

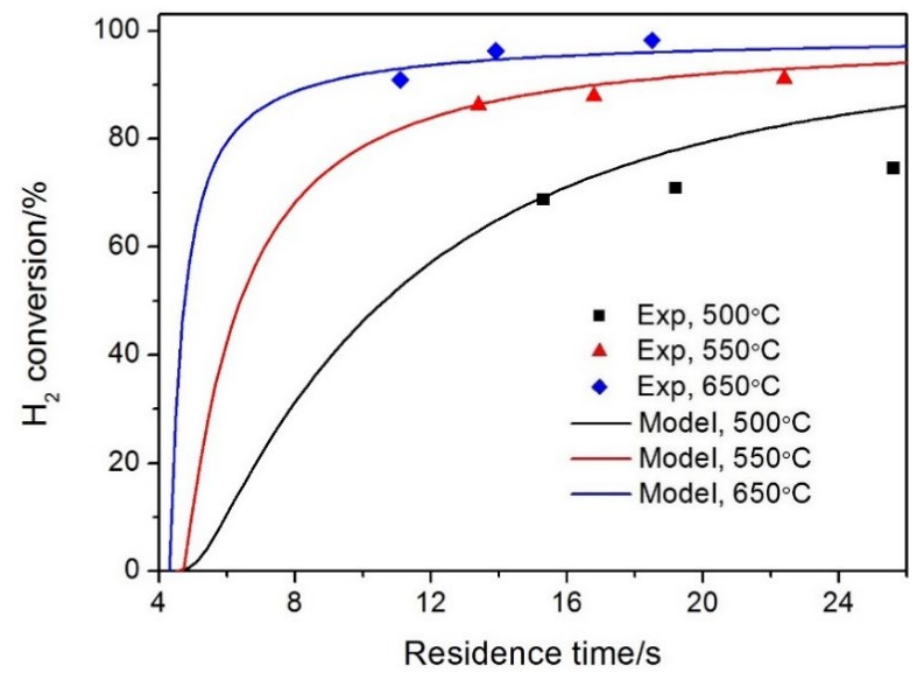

Figure 2. Comparison of measured ${ }^{11}$ and predicted hydrogen conversion as a function of residence time at different temperatures. The modeling curves have been shifted in time to match the first data point. Initial condition: $\left[\mathrm{H}_{2}\right]_{0}=9.3 \times 10^{-5} \mathrm{wt} \%,\left[\mathrm{O}_{2}\right]_{0}=8.4$ $\times 10^{-6} \mathrm{wt} \%$. The flow rate is $0.75 \mathrm{~g} / \mathrm{min}$ and the pressure is $25 \mathrm{MPa}$.

\subsubsection{Comparison with the data of Li et al.}

Li et al. ${ }^{12}$ used a different experimental approach. Instead of dissolving hydrogen and oxygen into water, they produced supercritical $\mathrm{H}_{2} \mathrm{O} / \mathrm{H}_{2}$ mixtures by SCW gasification 
of $2 \mathrm{wt} \%$ methanol solution and supercritical $\mathrm{H}_{2} \mathrm{O} / \mathrm{O}_{2}$ mixtures by pyrolysis of a $\mathrm{H}_{2} \mathrm{O}_{2}$ solution. The inlet hydrogen concentrations in their experiments were several orders of magnitude higher than those employed by Holgate et al. and Kallikrakas et al. A small amount of $\mathrm{CO}_{2}$ (around $0.7 \mathrm{~mol} \%$ ) as well as trace amounts of $\mathrm{CO}$ and $\mathrm{CH}_{4}$ were present in the system as by-products of methanol gasification. Even though the mass flow rate in their experiments was kept nearly constant, the pressure fluctuated with a maximum amplitude of 0.3 MPa because of the instability of the gas-liquid two-phase flow. Due to the high inlet hydrogen concentrations more heat was released by reaction, but the fluid temperatures measured at different positions differed no more than $6{ }^{\circ} \mathrm{C}$.

The experiments of $\mathrm{Li}$ et al. ranged from fuel-lean to fuel-rich conditions, with fuel/oxygen equivalence ratios $\varphi$ of $0.46-1.23$. Note that the experimental data under fuel-rich conditions and also some data at the short residence times was not included in Ref. 12 and are previously unpublished. The experimental data are compared with the model predictions in Figure 3. The effect of trace quantities of $\mathrm{CO}$ and $\mathrm{CH}_{4}$ on hydrogen oxidation was considered in the modeling. According to the experimental results of $\mathrm{Li}$ et al., ${ }^{12}$ the methanol gasification efficiency was about $98.5 \%$ and could be regarded to be complete. The composition of product gas was nearly constant, consisting of 72.9 $\mathrm{mol} \% \mathrm{H}_{2}, 23.3 \mathrm{~mol} \% \mathrm{CO}_{2}, 0.7 \% \mathrm{~mol}^{2} \mathrm{CO}$ and $0.2 \mathrm{~mol} \% \mathrm{CH}_{4}$. The amounts of $\mathrm{CO}$ and $\mathrm{CH}_{4}$ were $0.9 \%$ and $0.3 \%$ of the amount of $\mathrm{H}_{2}$, respectively. Modeling predictions indicate that the influence of $\mathrm{CO}$ and $\mathrm{CH}_{4}$ on the hydrogen oxidation reaction is negligible.

The agreement between model predictions and experimental data in Figure 3 is very satisfactory at low temperatures. Above $550{ }^{\circ} \mathrm{C}$, however, the hydrogen conversion is overpredicted. An overall evaluation of the model performance is shown in Figure S5 (SI). 


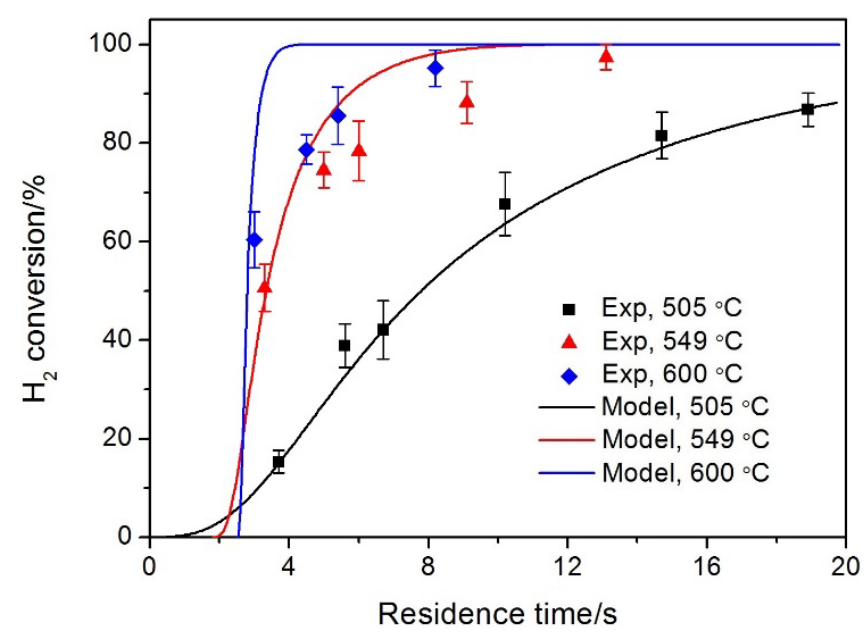

(a)

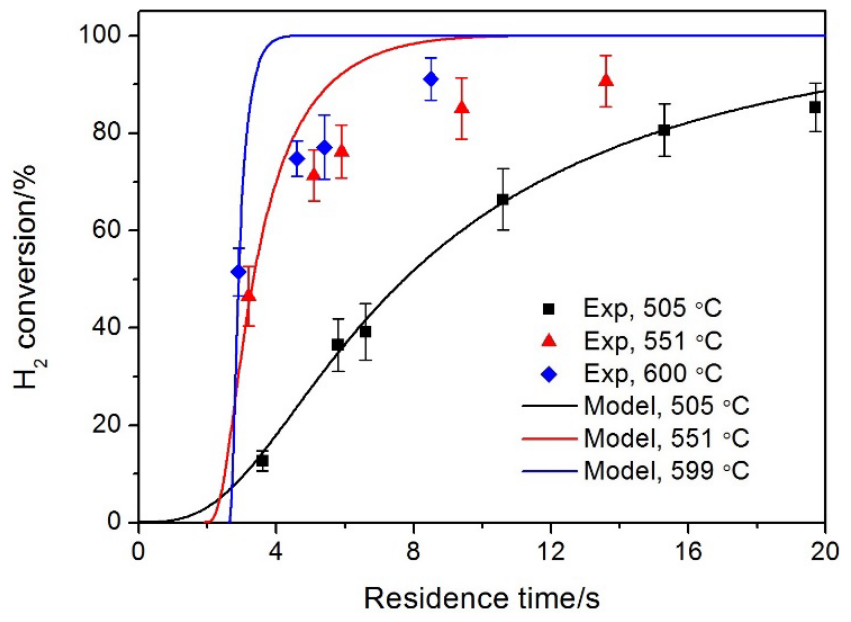

(b)

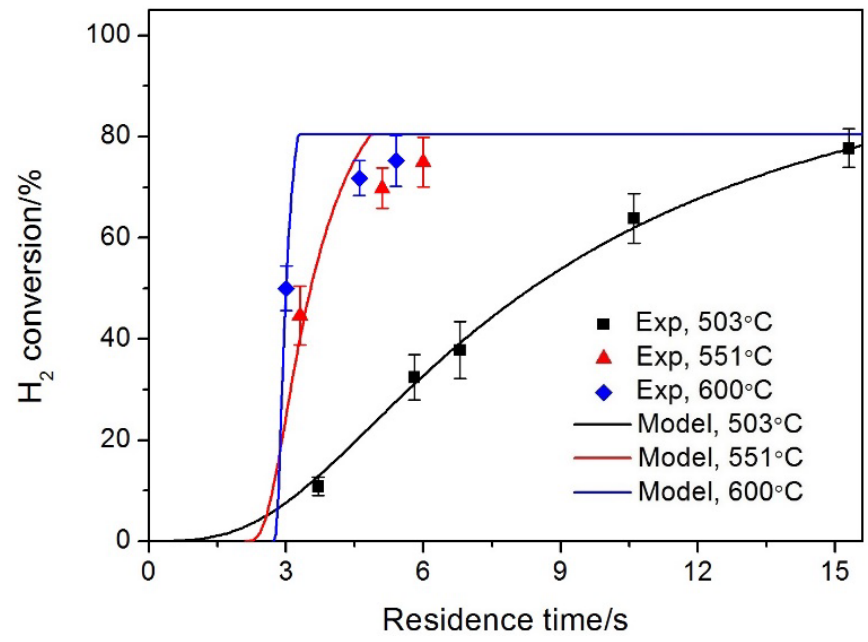

(c)

Figure 3. Comparison of measured ${ }^{12}$ and predicted hydrogen conversion as a function of residence time under different conditions: (a) $\varphi=0.46$; (b) $\varphi=0.91$; (c) $\varphi=1.23$. 
The modeling curves have been shifted in time to match the point where $50 \%$ of the experimental hydrogen conversion occurs.

\subsection{Evaluation of experimental uncertainties}

Both experimental uncertainties and model deficiencies may be responsible for the discrepancies between data and modeling results. The effects of experimental uncertainties on the modeling results are evaluated in this section.

\subsubsection{Isothermal approximation}

In the modeling, the reactors were assumed to be isothermal. In experiments, the reactors were put in sand baths and the reactor temperatures might vary at different positions. For the experiments of $\mathrm{Li}$ et al. ${ }^{12}$ that had the highest heat release, the adiabatic temperature increase of the fluid was estimated to be $24{ }^{\circ} \mathrm{C}$. However, the maximum difference between measured fluid temperatures was only $6{ }^{\circ} \mathrm{C}$ and the maximum difference among the measured temperatures of the reactor wall was $8{ }^{\circ} \mathrm{C}$. Thus, most of the heat released by reaction was removed by the sand bath and the isothermal assumption appears reasonable.

\subsubsection{Plug flow approximation}

The experimental data in the above section were modeled assuming that the systems could be described as ideal plug-flow reactors. The presence of radial velocity gradients, however, causes deviations from plug-flow. A useful measure of the radial velocity gradient is the longitudinal dispersion, ${ }^{54,55}$ which characterizes the spreading of fluid elements as a result of different local flow velocities and molecular diffusion. This process is represented by the dispersion coefficient $D_{\text {disp, }}$ which can be determined from the following correlation from Levenspiel, ${ }^{54}$

$$
D_{\text {disp }}=D+\frac{u^{2} d_{r}^{2}}{192 D}
$$

Here, $D$ is the self-diffusion coefficient of SCW, $u$ is the flow velocity and $d_{r}$ is the reactor diameter. A large value of $D_{\text {disp }}$ indicates rapid spreading (mixed flow) whereas lower values indicate slower spreading, with the limit $D_{\text {disp }}=0$ corresponding to ideal plug flow. 
The dimensionless group $D_{\text {disp }} / u d_{r}$, is useful to characterize the optimum relation between values of $D_{\text {disp }}, u$ and $D$. The Reynolds number (Re), charactering the intensity of turbulence, is expressed as

$$
\operatorname{Re}=\frac{\rho u d_{r}}{\mu}
$$

Here $\mu$ is the fluid viscosity and $\rho$ is the fluid density. The Peclet number Pe (also known as the Bodenstein number, Bo), representing the ratio between mass transfer by convection and diffusion, is expressed as the product of the Reynolds number and the Schmidt number (Sc).

$$
P e=\operatorname{Re} \times S c=\frac{\rho u d_{r}}{\mu} \frac{\mu}{\rho D}=\frac{u d_{r}}{D}
$$

Figure 4a correlates $D_{\mathrm{disp}} / u d_{r}$ with Pe (Bo) for steady laminar pipe flow. The best plugflow approximation is obtained at bottom of the curve where the axial dispersion in the laminar pipe flow is low. The experimental conditions of Kalligragas et al. ${ }^{11}$ are also depicted, marked in red, in Figure 4a. The values of $D_{\text {disp }} / u d_{r}$ are larger than 1 and accordingly, their experiments deviate from plug-flow conditions. The relatively high values of Pe indicate that the dispersion is mainly caused by axial convection rather than molecular diffusion. Figure $4 \mathrm{~b}$ correlates $D_{\text {disp }} / u d_{r}$ with Re for turbulent flow in pipes. The experimental conditions of Holgate et al. ${ }^{6,8}$ and Li et al. ${ }^{12}$ lie in the shadow area of the figure, also showing deviation from plug flow idealization. The Sc and $\mathrm{Re}$ numbers in their experiments are at the ranges of 0.98-1 and 2300-5800, respectively.

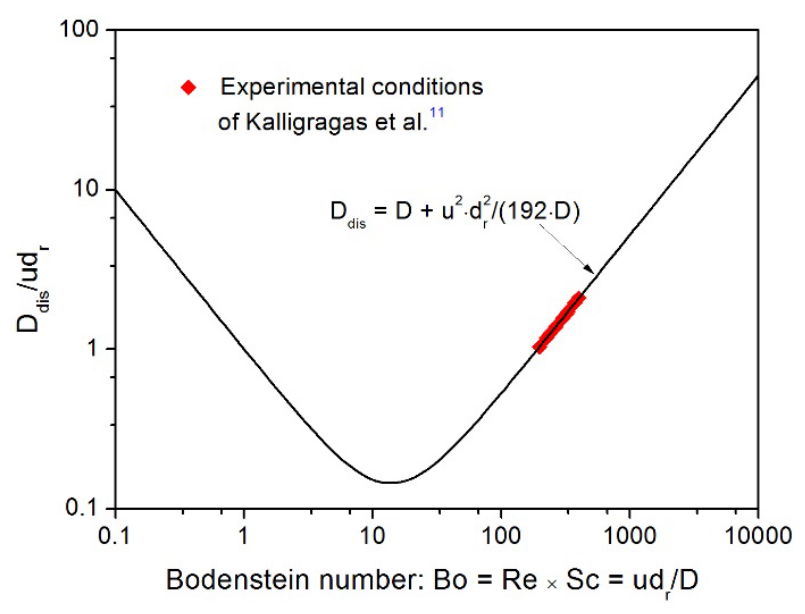

(a) 


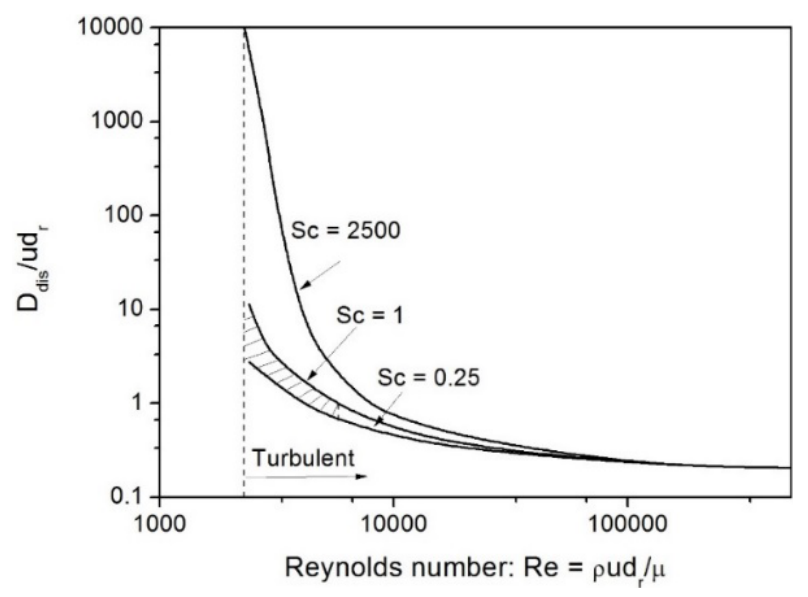

(b)

Figure 4. Intensity of axial dispersion $\left(\mathrm{D}_{\mathrm{dis}} / \mathrm{ud}_{\mathrm{r}}\right)$ correlated with (a) the Bodenstein number, in the laminar flow regime relevant for the experimental conditions of Kalligragas et al. ${ }^{11}$ (marked in red); (b) the Reynolds number, at the turbulent flow regime relevant for the experimental conditions of Holgate et al. ${ }^{6,8}$ and $\mathrm{Li}$ et al. ${ }^{12}$ (marked by the shadow area).

The fact that the SCWO experiments deviate from plug-flow behavior may partly explain the discrepancy between experimental data and modeling results. The major difference was overprediction of the degree of $\mathrm{H}_{2}$ oxidation at long reaction times. Significant dispersion in the experiments would serve to inhibit a high fractional conversion of the fuel. It suggests that an optimization of the kinetic model to provide a more accurate description of the experimental results is not warranted.

\subsubsection{Mixing effects}

As mentioned in section 3.1, all the reported SCWO experiments involve in-situ mixing of reactants. An assumption of instantaneous mixing may lead to errors in the predicted hydrogen oxidation rate. The mixing process mainly affects the induction time. Since the mixing times are much shorter than the reactor residence times, ${ }^{6}$ the experimental data obtained are all post-induction. By shifting the modeling curves to match the point where $50 \%$ of the experimental hydrogen conversion occurs, we effectively eliminate the uncertainty caused by mixing in the modeling results, as 
discussed in detail elsewhere. ${ }^{52}$ The predicted hydrogen conversion without any time shifting are compared with experimental data ${ }^{6,8,11,12}$ to exhibit the mixing effect on modeling results, as shown in Figures S6-S8 (SI).

\subsubsection{Surface reactions}

It is recognized that gas-phase hydrogen oxidation may be affected by reactions on the reactor surface. ${ }^{56}$ It is important to evaluate to what extent similar effects are present under supercritical conditions. Surface reactions may involve termination of radicals, inhibiting the oxidation reaction. Surface inhibition would be most pronounced at low pressures, while under SCWO conditions diffusion of radicals to the wall is inhibited by the high density and viscosity. ${ }^{30}$ The reactor wall may also catalyze hydrolysis at high temperatures. ${ }^{57}$ Small amounts of hydrogen are released through the interaction of water with metal surface, affecting the inlet hydrogen concentration. However, the hydrogen evolution rate is very slow and it can be neglected when the inlet hydrogen concentration is higher than $10^{-3} \mathrm{~mol} / \mathrm{L} .^{57}$

Holgate et al. ${ }^{8,58}$ conducted a set of experiments in a packed reactor to identify the effect of surface reactions on observed kinetics. They found that the added surface area in the packed reactor inhibited the oxidation reaction. However, the reduction in reaction rate was much less than directly proportional to the increase in surface area, implying that the role of the reactor surface was small in tubular reactor experiments. Even though the surface reactions could be partly responsible for the discrepancy between experimental data and modeling results, it is probably a minor effect.

\subsection{Reaction path and sensitivity analyses}

The model predictions are dominated by eight fast elementary reactions. The main reaction pathways for $\mathrm{H}_{2}$ under SCW conditions are portrayed in Figure 5. The initiation reaction is $\mathrm{H}_{2}+\mathrm{O}_{2}$, producing $\mathrm{H}$ and $\mathrm{HO}_{2}$ radicals (-R12). Dissociation of $\mathrm{H}_{2} \mathrm{O}(\mathrm{R} 4)$ was proposed by Holgate et al. $^{6}$ as the initiation reaction, but it is unlikely to be important in the temperature range of interest since the activation energy of this step is 
very high. Atomic hydrogen reacts rapidly with $\mathrm{O}_{2}$ to produce $\mathrm{HO}_{2}$ through (R9). Most $\mathrm{HO}_{2}$ radicals react with $\mathrm{H}_{2}$ to form $\mathrm{H}_{2} \mathrm{O}_{2}$ (-R16), serving as the main pathway for $\mathrm{H}_{2} \mathrm{O}_{2}$ production. $\mathrm{H}_{2} \mathrm{O}_{2}$ can also be produced by the self-reaction of $\mathrm{HO}_{2}(\mathrm{R} 14)$. The $\mathrm{H}_{2} \mathrm{O}_{2}$ then undergoes rapid decomposition (R15) to yield $\mathrm{OH}$ radicals. The $\mathrm{H}+\mathrm{O}_{2}=\mathrm{O}+\mathrm{OH}$ reaction (R5) provides an alternative pathway for the production of $\mathrm{OH}$, but it is less important than (R15). Molecular hydrogen $\mathrm{H}_{2}$ is primarily oxidized by $\mathrm{OH}$ radicals via (R7), completing the last step of the chain reaction. The reactions $\mathrm{OH}+\mathrm{HO}_{2}=\mathrm{O}_{2}+$ $\mathrm{H}_{2} \mathrm{O}(\mathrm{R} 13)$ and $\mathrm{OH}+\mathrm{H}_{2} \mathrm{O}_{2}=\mathrm{HO}_{2}+\mathrm{H}_{2} \mathrm{O}(\mathrm{R} 19)$ serve as termination steps.

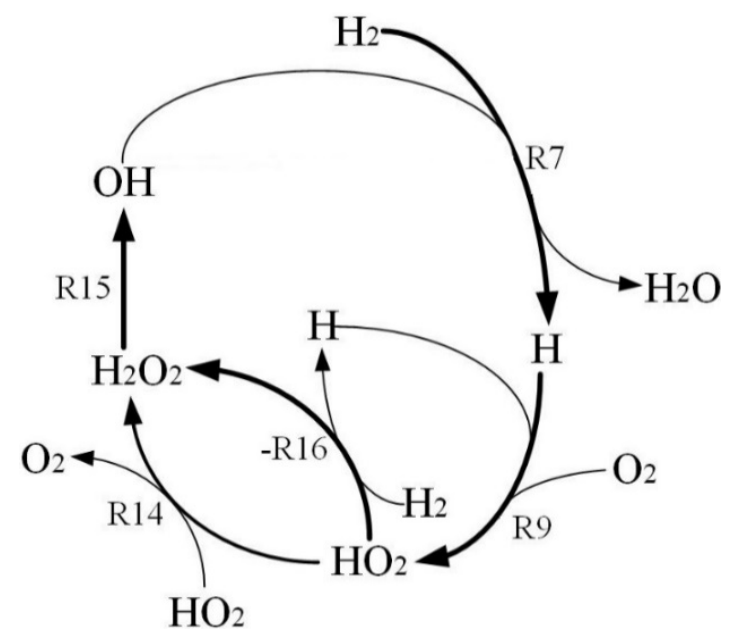

Figure 5. Major free-radical reaction pathways in elementary reaction model for hydrogen oxidation under supercritical conditions.

A sensitivity analysis is shown in Figure 6. Reactions not appearing in the figure exhibit sensitivities more than an order of magnitude lower than those shown. The high sensitivity of the model predictions to $\mathrm{OH}+\mathrm{H}_{2}=\mathrm{H}+\mathrm{H}_{2} \mathrm{O}(\mathrm{R} 7)$ and $\mathrm{HO}_{2}+\mathrm{H}_{2}=\mathrm{H}+$ $\mathrm{H}_{2} \mathrm{O}_{2}$ (-R16) is expected, since they are both main oxidizing steps, similar to what has been observed in the gas-phase at high pressure and intermediate temperatures. ${ }^{14}$ Reaction -R16 also serves as the main pathway for the conversion at supercritical state of hydrogen to $\mathrm{H}_{2} \mathrm{O}_{2}$, which is responsible for the production of $\mathrm{OH}$ radical. The primary steps for conversion of $\mathrm{O}_{2}, \mathrm{H}+\mathrm{O}_{2}=\mathrm{O}+\mathrm{OH}(\mathrm{R} 5)$ and $\mathrm{H}+\mathrm{O}_{2}(+\mathrm{M})=\mathrm{HO}_{2}$ $(+\mathrm{M})(\mathrm{R} 9)$, exhibit small sensitivity coefficients and even large variations in their rate 
constants will not affect the model predictions. This is different from gas-phase combustion below the second explosion limit, where model predictions are very sensitive to $\mathrm{R} 5$ as the main branching reaction.

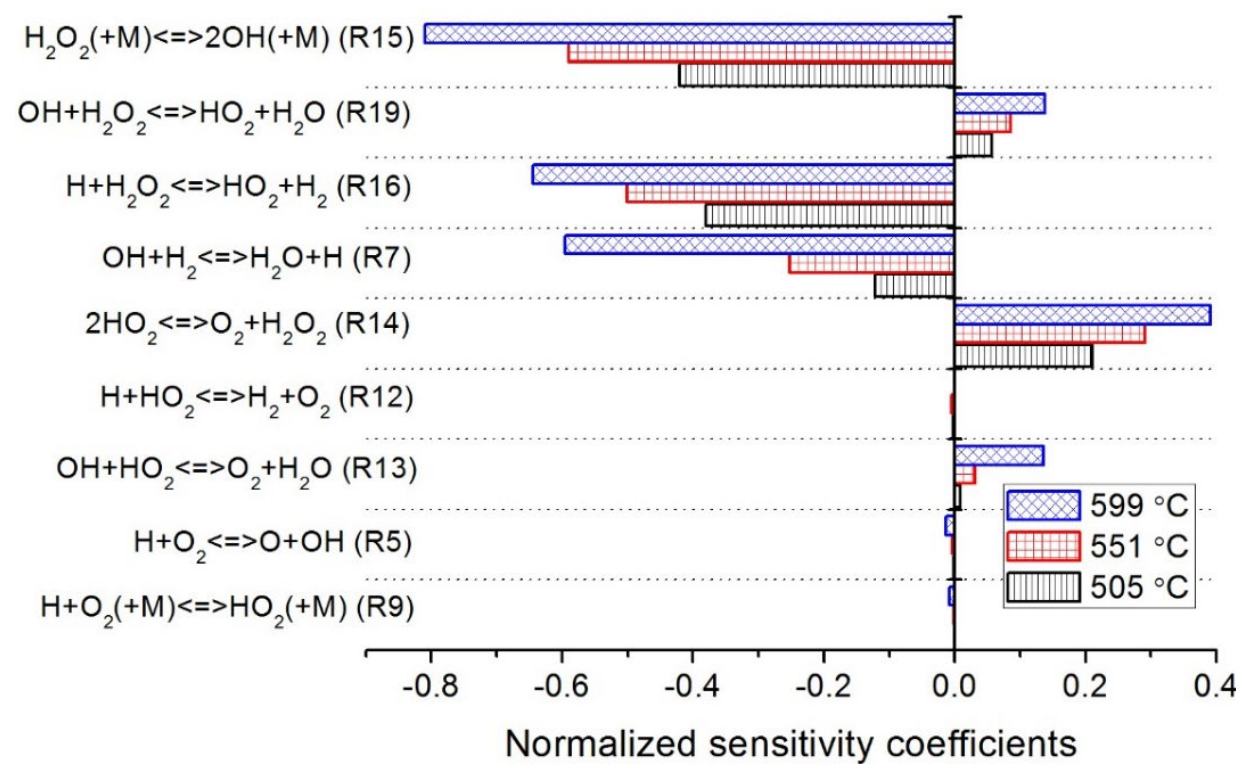

Figure 6. Sensitivity coefficients of reactions for a flow reactor ${ }^{12}$ calculated by using the present model. Initial conditions: $\mathrm{H}_{2}=2.30 \mathrm{~mol} \%, \mathrm{O}_{2}=1.24 \mathrm{~mol} \%, \mathrm{CO}_{2}=0.72$ mol $\%$ and $\mathrm{H}_{2} \mathrm{O}=95.74 \mathrm{~mol} \%$ at $23.6 \mathrm{MPa}$. The sensitivity coefficients are taken at the time when $\mathrm{H}_{2}$ consumption rate is highest.

The net rate profiles of the high-sensitivity reactions are shown in Figure 7 . The net rate is defined as the rate in the forward direction minus the rate in the reverse direction. The rates of some reactions are too close to be distinguishable at the scale of the figure. It is observed that the rates of all reactions speed up at the initial stage. After reaching peak points, the reaction rates decrease gradually. The rates of different reactions vary among several orders of magnitude, determining to what extent they can influence the model predictions.

Figure 8 shows the time evolution of molar fractions of $\mathrm{H}_{2} \mathrm{O}_{2}$ and free radicals. The radical species concentrations rise rapidly initially. After reaching the maximum value, the concentration of $\mathrm{OH}$ levels out while the concentrations of other radicals decrease gradually. The $\mathrm{OH}$ level is replenished by the slow decomposition of $\mathrm{H}_{2} \mathrm{O}_{2}$. The $\mathrm{HO}_{2}$ 
radical is by far the most abundant radical, consistent with observations in high-pressure gas-phase combustion. ${ }^{14}$

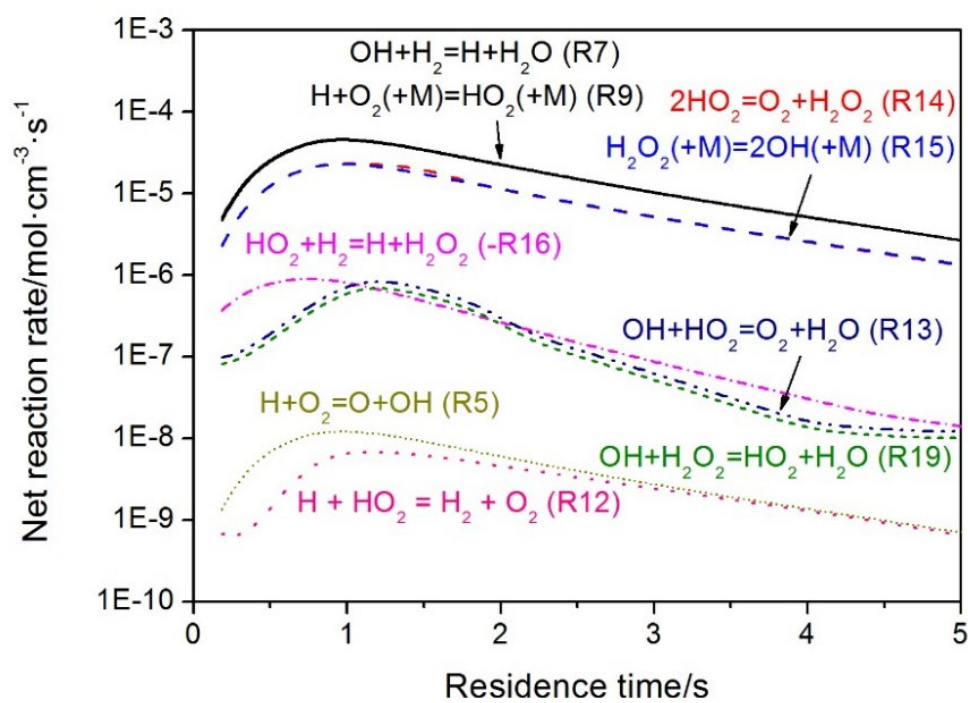

Figure 7. Net reaction rate profiles for major elementary reactions predicted by the present kinetic model. Modeling conditions: $551^{\circ} \mathrm{C}$ and $23.6 \mathrm{MPa}, \mathrm{H}_{2}=2.30 \mathrm{~mol} \%$, $\mathrm{O}_{2}=1.24 \mathrm{~mol} \%, \mathrm{CO}_{2}=0.72 \mathrm{~mol} \%$ and $\mathrm{H}_{2} \mathrm{O}=95.74 \mathrm{~mol} \%$.

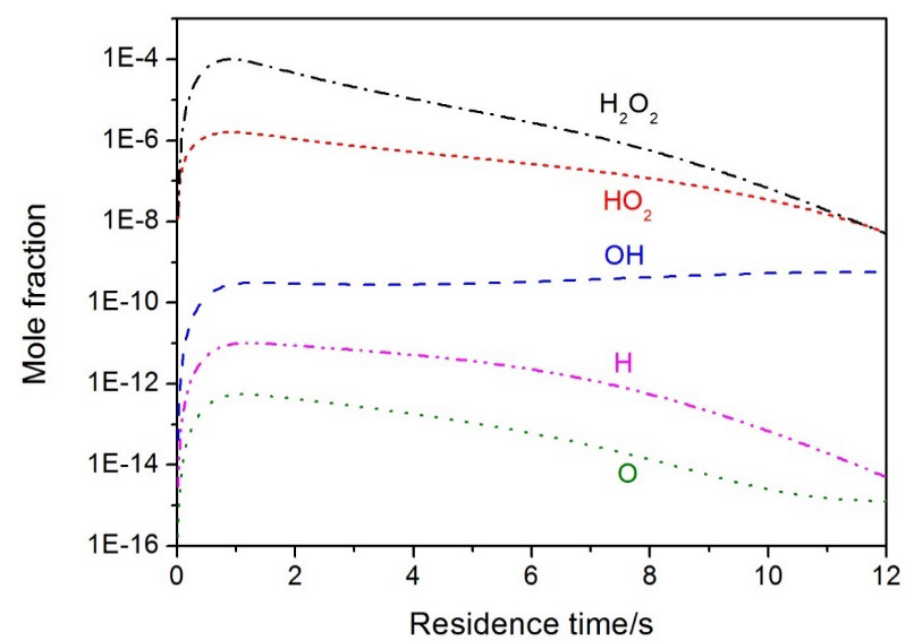

Figure 8. Predicted free radicals profiles for conditions the same as those in Figure 7.

\subsection{Practical implications}

Predictions with the detailed kinetic model can be useful to assess the impact of process parameters and facilitate design improvements in SCWO, if care is taken to consider the flow characteristics. Two parameters of importance in industrial 
applications of SCWO are the pressure and the $\mathrm{CO}_{2}$ concentration; they may influence the hydrogen oxidation rate and thereby have implications for the design and steady operation of the reactors. In this section, the model is used to explore the effects of these parameters on the reaction kinetics.

\subsubsection{Effect of pressure}

Figure 9 compares the hydrogen conversion rates at $551^{\circ} \mathrm{C}$ at different pressures. It can be seen that increasing the pressure from 23.6 to $27 \mathrm{MPa}$ only has a small impact on the hydrogen conversion rate. Pressure can influence the reaction kinetics in two ways. First, a change in pressure may affect the rates of pressure-dependent reactions by changing the third-body concentration. Since the reaction rates of reactions (R9) and (R15) are very close to their high-pressure limits at supercritical pressures, the effect of higher pressure on the two reactions will be small. Second, an increase in pressure causes a higher water concentration. Water is a product of reactions (R13) and (R19), which serve to inhibit the hydrogen oxidation. Increasing the water concentration causes a minor decrease in their net reaction rates, promoting slightly hydrogen oxidation.

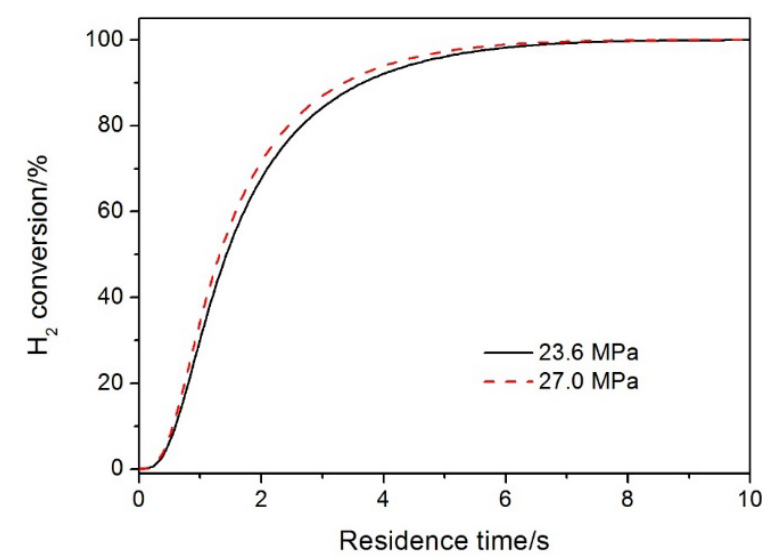

Figure 9. $\mathrm{H}_{2}$ conversion profiles at $551{ }^{\circ} \mathrm{C}$ at different pressures. Initial concentrations of hydrogen and oxygen are the same as those in Figure 7.

\subsubsection{Effect of $\mathrm{CO}_{2}$ concentration}

Figure 10 compares hydrogen conversion rates at $551{ }^{\circ} \mathrm{C}$ for different $\mathrm{CO}_{2}$ 
concentrations. It is found that an increased $\mathrm{CO}_{2}$ fraction in supercritical mixtures slows down the hydrogen oxidation rate, but it is only a minor effect. A high $\mathrm{CO}_{2}$ concentration affects the reaction kinetics in two ways. First, the collisional efficiency of $\mathrm{CO}_{2}$ is smaller than that of $\mathrm{H}_{2} \mathrm{O}$. Considering the reaction rates of pressure-dependent reactions are very close to their high-pressure limits under supercritical conditions, this influence is small. Second, a higher $\mathrm{CO}_{2}$ concentration implies a lower water concentration, facilitatating the net reaction rates of (R13) and (R19).

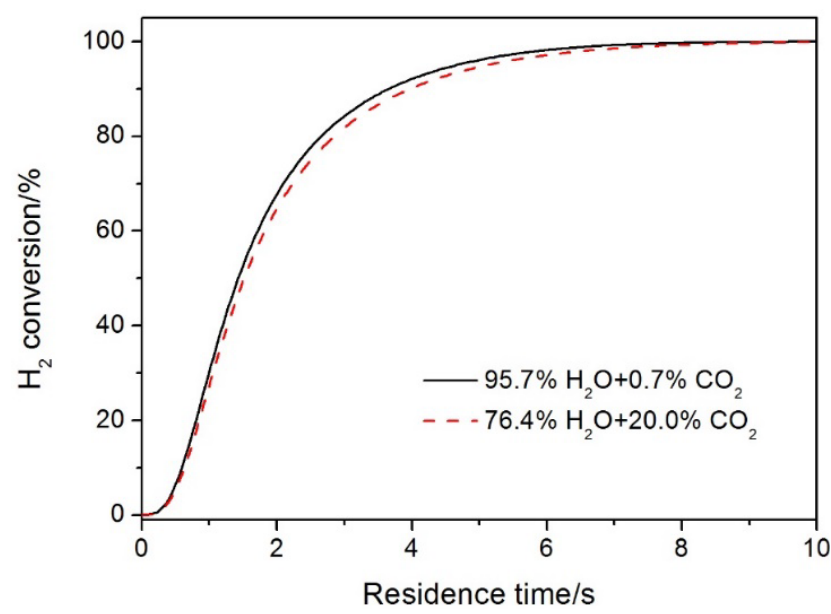

Figure 10. $\mathrm{H}_{2}$ conversion profiles at $551{ }^{\circ} \mathrm{C}$ and $23.6 \mathrm{MPa}$ under different $\mathrm{CO}_{2}$ concentration conditions. Solid line: $\left[\mathrm{H}_{2}\right]_{0}=2.4 \mathrm{~mol} \%,\left[\mathrm{O}_{2}\right]_{0}=1.2 \mathrm{~mol} \%,\left[\mathrm{H}_{2} \mathrm{O}\right]_{0}=$ $95.7 \mathrm{~mol} \%,\left[\mathrm{CO}_{2}\right]_{0}=0.7 \mathrm{~mol} \%$. Dash line: $\left[\mathrm{H}_{2}\right]_{0}=2.4 \mathrm{~mol} \%,\left[\mathrm{O}_{2}\right]_{0}=1.2 \mathrm{~mol} \%,\left[\mathrm{H}_{2} \mathrm{O}\right]_{0}$ $=6.4 \mathrm{~mol} \%,\left[\mathrm{CO}_{2}\right]_{0}=20.7 \mathrm{~mol} \%$.

\section{Conclusions}

This study presents a new detailed kinetic model developed for hydrogen oxidation in supercritical $\mathrm{H}_{2} \mathrm{O} / \mathrm{CO}_{2}$ mixtures. Revisions were made to an existing gas-phase hydrogen oxidation kinetic model ${ }^{14}$ to account for the SCW environment. Thermodynamic values of selected species at supercritical pressure were obtained from the NIST database. Recent improvements in the kinetic parameters were incorporated into the model and the effect of water clusters on the rate constants of some important elementary reactions was discussed. The model was tested against the experimental 
data available in literature for SCWO of hydrogen with good results. The observed discrepancies were largely attributed to experimental artifacts, mainly deviation from ideal plug flow. Analysis of the calculations showed that the reaction $\mathrm{H}_{2}+\mathrm{O}_{2}=\mathrm{HO}_{2}+$ $\mathrm{H}(-\mathrm{R} 12)$ acts as the primary initiation reaction in $\mathrm{H}_{2} / \mathrm{O}_{2}$ chemistry under supercritical conditions. The reaction $\mathrm{H}_{2} \mathrm{O}_{2}(+\mathrm{M})=\mathrm{OH}+\mathrm{OH}(+\mathrm{M})(\mathrm{R} 15)$, together with $\mathrm{HO}_{2}+\mathrm{H}_{2}$ $=\mathrm{H}_{2} \mathrm{O}_{2}+\mathrm{H}(-\mathrm{R} 16)$ and $\mathrm{OH}+\mathrm{H}_{2}=\mathrm{H}+\mathrm{H}_{2} \mathrm{O}(\mathrm{R} 7)$, were found to be most important for modeling results. The model was used to assess the importance of variations in pressure and $\mathrm{CO}_{2}$ concentration on SCW hydrogen oxidation.

\section{Acknowledgements}

This work is financially supported by the National Key Research and Development Program of China (2016YFB0600102) and the National Natural Science Foundation of China (No. 51925602 \& No. 51888103). Guoxing Li wishes to acknowledge funding from China Scholarship Council (CSC) (No. 201906280347) for his stay at the Technical University of Denmark.

\section{References}

(1) Marban, G.; Valdes-Solis, T. Towards the hydrogen economy? Int. J. Hydrogen Energy 2007, $32(12), 1625-1637$.

(2) Guo, L.; Jin, H. Boiling coal in water: Hydrogen production and power generation system with zero net $\mathrm{CO}_{2}$ emission based on coal and supercritical water gasification. Int. J. Hydrogen Energy 2013, 38 (29), 12953-12967.

(3) Chen, Z.; Zhang, X.; Han, W.; Gao, L.; Li, S. A power generation system with integrated supercritical water gasification of coal and $\mathrm{CO}_{2}$ capture. Energy 2018, 142, 723-730.

(4) Qian, L.; Wang, S.; Ren, M.; Wang, S. Co-oxidation effects and mechanisms between sludge and alcohols (methanol, ethanol and isopropanol) in supercritical water. Chem. Eng. J. 2019, 366, $223-234$

(5) Falamarzian, S.; Tavakoli, O.; Zarghami, R.; Faramarzi, M. A. Catalytic hydrothermal treatment of pharmaceutical wastewater using sub- and supercritical water reactions. J. Supercrit. Fluids 2014, 95, 265-272. 
(6) Holgate, H. R.; Tester, J. W. Fundamental kinetics and mechanisms of hydrogen oxidation in supercritical water. Combust. Sci. Technol. 1993, 88 (5-6), 369-397.

(7) Yetter, R. A.; Dryer, F. L.; Rabitz, H. A comprehensive reaction mechanism for carbon monoxide/hydrogen/oxygen kinetics. Combust. Sci. Technol. 1991, 79 (1-3), 97-128.

(8) Holgate, H. R.; Tester, J. W. Oxidation of hydrogen and carbon monoxide in sub and supercritical water: Reaction kinetics, pathways, and water-density effects. 1. Experimental results. J. Phys. Chem. 1994, 98 (3), 800-809.

(9) Alkam, M. K.; Pai, V. M.; Butler, P. B.; Pitz, W. J. Methanol and hydrogen oxidation kinetics in water at supercritical states. Combust. Flame 1996, 106 (1-2), 110-130.

(10) Brock, E. E.; Savage, P. E. Detailed chemical kinetics model for supercritical water oxidation of $\mathrm{C}_{1}$ compounds and $\mathrm{H}_{2}$. AIChE J. 1995, 41 (8), 1874-1888.

(11) Kallikragas, D. T.; Svishchev, I. M.; Choudhry, K. I. Rate of Hydrogen Combustion in Supercritical Water. J. Phys. Chem. C 2017, 121 (1), 80-84.

(12) Li, G.; Wang, H.; Lu, Y. Kinetic study on hydrogen oxidation in supercritical $\mathrm{H}_{2} \mathrm{O} / \mathrm{CO}_{2}$ mixtures. Fuel Proc. Technol. 2019, 193, 123-130.

(13) Li, G.; Lu, Y.; Qi, S. Investigation of hydrogen oxidation in supercritical $\mathrm{H}_{2} \mathrm{O} / \mathrm{CO}_{2}$ mixtures using ReaxFF molecular dynamics simulation. J. Supercrit. Fluids 2020, 155, 104661.

(14) Hashemi, H.; Christensen, J. M.; Gersen, S.; Glarborg, P. Hydrogen oxidation at high pressure and intermediate temperatures: Experiments and kinetic modeling. Proc. Combust. Inst. 2015, 35, 553-560.

(15) Mueller, M. A.; Kim, T. J.; Yetter, R. A.; Dryer, F. L. Flow reactor studies and kinetic modeling of the $\mathrm{H}_{2} / \mathrm{O}_{2}$ reaction. Int. J. Chem. Kinet. 1999, 31 (2), 113-125.

(16) Li, J.; Zhao, Z.; Kazakov, A.; Chaos, M.; Dryer, F. L. An updated comprehensive kinetic model of hydrogen combustion. Int. J. Chem. Kinet. 2004, 36 (10), 566-575.

(17) Burke, M. P.; Chaos, M.; Ju, Y.; Dryer, F. L.; Klippenstein, S. J. Comprehensive $\mathrm{H}_{2} / \mathrm{O}_{2}$ kinetic model for high-pressure combustion. Int. J. Chem. Kinet. 2012, 44 (7), 444-474.

(18) Conaire, M. Ó.; Curran, H. J.; Simmie, J. M.; Pitz, W. J.; Westbrook, C. K. A comprehensive modeling study of hydrogen oxidation. Int. J. Chem. Kinet. 2004, 36 (11), 603-622. 
(19) Keromnes, A.; Metcalfe, W. K.; Heufer, K. A.; Donohoe, N.; Das, A. K.; Sung, C. J.; et al. An experimental and detailed chemical kinetic modeling study of hydrogen and syngas mixture oxidation at elevated pressures. Combust. Flame 2013, 160 (6), 995-1011.

(20) Konnov, A. A. Remaining uncertainties in the kinetic mechanism of hydrogen combustion. Combust. Flame 2008, 152 (4), 507-528.

(21) Konnov, A. A. On the role of excited species in hydrogen combustion. Combust. Flame 2015, $162(10), 3755-3772$.

(22) Konnov, A. A. Yet another kinetic mechanism for hydrogen combustion. Combust. Flame 2019, 203, 14-22.

(23) Varga, T.; Nagy, T.; Olm, C.; Zsely, I. G.; Palvolgyi, R.; Valko, E.; et al. Optimization of a hydrogen combustion mechanism using both direct and indirect measurements. Proc. Combust. Inst. 2015, 35, 589-596.

(24) Varga, T.; Olm, C.; Nagy, T.; Zsely, I. G.; Valko, E.; Palvolgyi, R.; et al. Development of a joint hydrogen and syngas combustion mechanism based on an optimization approach. Int. J. Chem. Kinet. 2016, 48 (8), 407-422.

(25) Davis, S. G.; Joshi, A. V.; Wang, H.; Egolfopoulos, F. An optimized kinetic model of $\mathrm{H}_{2} / \mathrm{CO}$ combustion. Proc. Combust. Inst. 2005, 30, 1283-1292.

(26) Sun, H.; Yang, S. I.; Jomaas, G.; Law, C. K. High-pressure laminar flame speeds and kinetic modeling of carbon monoxide/hydrogen combustion. Proc. Combust. Inst. 2007, 31, 439-446.

(27) Hong, Z.; Davidson, D. F.; Hanson, R. K. An improved $\mathrm{H}_{2} / \mathrm{O}_{2}$ mechanism based on recent shock tube/laser absorption measurements. Combust. Flame 2011, 158 (4), 633-644.

(28) Olm, C.; Zsely, I. G.; Palvolgyi, R.; Varga, T.; Nagy, T.; Curran, H. J.; Turanyi, T. Comparison of the performance of several recent hydrogen combustion mechanisms. Combust. Flame 2014, 161 (9), 2219-2234.

(29) Wu, B.C.; Klein, M.T.; Sandler, S.I. Solvent Effects on Reactions in Supercritical Fluids. Ind. Eng. Chem. Res. 1991, 30 (5), 822-828.

(30) Akiya, N.; Savage, P. E. Role of water for chemical reactions in high-temperature water. Chem. Rev. 2002, 102 (8), 2725-2750. 
(31) Alasiri, H.; Klein, M. T. Solvent effects for the hydrolysis reaction of dibenzyl ether in supercritical water: A combined density functional theory and molecular dynamics simulation study. Energy Fuels 2019, 33 (12), 12685-12689.

(32) Hashemi, H.; Christensen, J. M.; Gersen, S.; Levinsky, H.; Klippenstein, S. J.; Glarborg, P. High-pressure oxidation of methane. Combust. Flame 2016, 172, 349-364.

(33) ANSYS Chemkin-Pro 18.2, ANSYS, San Diego, 2017.

(34) Peng, D. Y.; Robinson, D. B. A new two-constant equation of state. Ind. Eng. Chem. Fundamen. 1976, 15 (1), 59-64.

(35) Janik, I.; Bartels, D. M.; Marin, T. W.; Jonah, C. D. Reaction of $\mathrm{O}_{2}$ with the hydrogen atom in water up to $350{ }^{\circ} \mathrm{C} . J$. Phys. Chem. A 2007, 111 (1), 79-88.

(36) Fernandes, R. X.; Luther, K.; Troe, J.; Ushakov, V. G. Experimental and modelling study of the recombination reaction $\mathrm{H}+\mathrm{O}_{2}(+\mathrm{M}) \rightarrow \mathrm{HO}_{2}(+\mathrm{M})$ between 300 and $900 \mathrm{~K}, 1.5$ and 950 bar, and in the bath gases $\mathrm{M}=\mathrm{He}, \mathrm{Ar}$, and $\mathrm{N}_{2}$. Phys. Chem. Chem. Phys. 2008, 10 (29), 4313-4321.

(37) Troe, J. Detailed modeling of the temperature and pressure dependence of the reaction $\mathrm{H}+\mathrm{O}_{2}$ $(+\mathrm{M}) \rightarrow \mathrm{HO}_{2}(+\mathrm{M})$. Proc. Combust. Inst. 2000, 28, 1463-1469.

(38) Shao, J.; Choudhary, R.; Susa, A.; Davidson, D. F.; Hanson, R. K. Shock tube study of the rate constants for $\mathrm{H}+\mathrm{O}_{2}+\mathrm{M} \rightarrow \mathrm{HO}_{2}+\mathrm{M}\left(\mathrm{M}=\mathrm{Ar}, \mathrm{H}_{2} \mathrm{O}, \mathrm{CO}_{2}, \mathrm{~N}_{2}\right)$ at elevated pressures. Proc. Combust. Inst. 2019, 37, 145-152.

(39) Janik, I.; Bartels, D. M.; Jonah, C. D. Hydroxyl radical self-recombination reaction and absorption spectrum in water up to $350^{\circ}$ C. J. Phys. Chem. A 2007, 111 (10), 1835-1843.

(40) Sellevag, S. R.; Georgievskii, Y.; Miller, J. A. Kinetics of the gas-phase recombination reaction of hydroxyl radicals to form hydrogen peroxide. J. Phys. Chem. A 2009, 113 (16), 44574467.

(41) Hong, Z.; Cook, R. D.; Davidson, D. F.; Hanson, R. K. A shock tube study of $\mathrm{OH}+\mathrm{H}_{2} \mathrm{O}_{2} \rightarrow$ $\mathrm{H}_{2} \mathrm{O}+\mathrm{HO}_{2}$ and $\mathrm{H}_{2} \mathrm{O}_{2}+\mathrm{M} \rightarrow 2 \mathrm{OH}+\mathrm{M}$ using laser absorption of $\mathrm{H}_{2} \mathrm{O}$ and $\mathrm{OH}$. J. Phys. Chem. A 2010, 114 (18), 5718-5727.

(42) Troe, J. The thermal dissociation/recombination reaction of hydrogen peroxide $\mathrm{H}_{2} \mathrm{O}_{2}(+\mathrm{M})$ $<=>2 \mathrm{OH}(+\mathrm{M})$ III. Analysis and representation of the temperature and pressure dependence over wide ranges. Combust. Flame 2011, 158 (4), 594-601. 
(43) Ellingson, B. A.; Theis, D. P.; Tishchenko, O.; Zheng, J.; Truhlar, D. G. Reaction of hydrogen atom with hydrogen peroxide. J. Phys. Chem. A 2007, 111 (51), 13554-13566.

(44) Tsang, W.; Hampson, R. F. Chemical kinetic data base for combustion chemistry. Part I. Methane and related compounds. J. Phys. Chem. Ref. Data 1986, 15 (3), 1087-1280.

(45) Baulch, D. L.; Bowman, C. T.; Cobos, C. J.; Cox, R. A.; Just, T.; Kerr, J. A.; et al. Evaluated kinetic data for combustion modeling: Supplement II. J. Phys. Chem. Ref Data 2005, 34 (3), $757-$ 1397.

(46) Hong, Z.; Davidson, D. F.; Barbour, E. A.; Hanson, R. K. A new shock tube study of the H + $\mathrm{O}_{2} \rightarrow \mathrm{OH}+\mathrm{O}$ reaction rate using tunable diode laser absorption of $\mathrm{H}_{2} \mathrm{O}$ near $2.5 \mu \mathrm{m}$. Proc. Combust. Inst. 2011, 33, 309-316.

(47) Lam, K. Y.; Davidson, D. F.; Hanson, R. K. A shock tube study of $\mathrm{H}_{2}+\mathrm{OH} \rightarrow \mathrm{H}_{2} \mathrm{O}+\mathrm{H}$ using OH laser absorption. Int. J. Chem. Kinet. 2013, 45 (6), 363-373.

(48) Burke, M. P.; Klippenstein, S. J.; Harding, L. B. A quantitative explanation for the apparent anomalous temperature dependence of $\mathrm{OH}+\mathrm{HO}_{2}=\mathrm{H}_{2} \mathrm{O}+\mathrm{O}_{2}$ through multi-scale modeling. Proc. Combust. Inst. 2013, 34, 547-555.

(49) Kappel, C.; Luther, K.; Troe, J. Shock wave study of the unimolecular dissociation of $\mathrm{H}_{2} \mathrm{O}_{2}$ in its falloff range and of its secondary reactions. Phys. Chem. Chem. Phys. 2002, 4 (18), 4392-4398. (50) Hong, Z.; Lam, K. Y.; Sur, R.; Wang, S.; Davidson, D. F.; Hanson, R. K. On the rate constants of $\mathrm{OH}+\mathrm{HO}_{2}$ and $\mathrm{HO}_{2}+\mathrm{HO}_{2}$ : a comprehensive study of $\mathrm{H}_{2} \mathrm{O}_{2}$ thermal decomposition using multispecies laser absorption. Proc. Combust. Inst. 2013, 34, 565-571.

(51) Hong, Z.; Cook, R. D.; Davidson, D. F.; Hanson, R. K. A shock tube study of OH $+\mathrm{H}_{2} \mathrm{O}_{2} \rightarrow$ $\mathrm{H}_{2} \mathrm{O}+\mathrm{HO}_{2}$ and $\mathrm{H}_{2} \mathrm{O}_{2}+\mathrm{M} \rightarrow 2 \mathrm{OH}+\mathrm{M}$ using laser absorption of $\mathrm{H}_{2} \mathrm{O}$ and $\mathrm{OH}$. J. Phys. Chem. A 2010, $114(18), 5718-5727$.

(52) Yetter, R. A.; Dryer, F. L.; Rabitz, H. Flow Reactor Studies of Carbon Monoxide/ Hydrogen/ Oxygen Kinetics. Combust. Sci. Technol. 1991, 79, 129-140.

(53) Roesler, J. F.; Yetter, R. A.; Dryer, F. L. Detailed kinetic modeling of moist CO oxidation inhibited by trace quantities of HCl. Combust. Sci. Technol. 1992, 85 (1-6), 1-22.

(54) Levenspiel, Octave. Chemical Reaction Engineering, 3rd edition; Wiley: New York, 1999. 
(55) Rasmussen, C. L.; Hansen, J.; Marshall, P.; Glarborg, P. Experimental measurements and kinetic modeling of $\mathrm{CO} / \mathrm{H}_{2} / \mathrm{O}_{2} / \mathrm{NO}_{\mathrm{x}}$ conversion at high pressure. Int. J. Chem. Kinet. 2008, 40 (8), $454-480$.

(56) Liang, W.; Law, C. K. An analysis of the explosion limits of hydrogen/oxygen mixtures with nonlinear chain reactions. Phys. Chem. Chem. Phys. 2018, 20 (2), 742-751.

(57) Choudhry, K. I.; Carvajal-Ortiz, R. A.; Kallikragas, D. T.; Svishchev, I. M. Hydrogen evolution rate during the corrosion of stainless steel in supercritical water. Corros. Sci. 2014, 83, 226-233.

(58) Holgate, H. R.; Tester, J. W. Oxidation of hydrogen and carbon monoxide in sub- and supercritical water: reaction kinetics, pathways, and water-density effects. 2. Elementary reaction modeling. J. Phys. Chem. B 1994, 98 (3), 810-822. 